\title{
Revisión- Comportamiento fisicoquímico de compuestos de caucho natural al adicionar residuos agroindustriales como cargas reforzantes
}

\author{
CARLOS ANDRÉs VARGAS ISAZA ${ }^{1}$ \\ WILLIAM URREGo YEPES ${ }^{1}$ \\ MaYra Yuliana ARbeláez Vergara ${ }^{1}$ \\ Claudia Johana SÁNCHEz MANOSALBA ${ }^{1}$
}

\section{Resumen}

Se lleva a cabo una revisión de investigaciones cuyo eje de estudio son los compuestos de caucho natural reforzados con cargas obtenidas a partir de residuos pos-industriales como el almidón de patata, bagazo de caña de azúcar, aserrín, cáñamo, tallo de plátano, cáscara de semilla de tamarindo, cascarilla de arroz, sílice obtenida de la cascarilla de arroz, fibra de coco, fibra de hoja de piña, lodo de mármol y ceniza de palma de aceite. Se evalúa para cada carga su composición, métodos de obtención y tratamientos de preparación, su incorporación en la matriz polimérica, las características de vulcanización de las mezclas y las propiedades físicas, químicas, térmicas y mecánicas.

Palabras claves: Caucho natural, residuos agroindustriales, refuerzos, negro de humo, sílice.

\section{Review- Physicochemical behaviour of natural rubber composites when adding agroindustrial wastes as reinforcing fillers}

\section{Abstract}

This work presents a review focused on natural rubber composites reinforced with obtained fillers from agroindustrial wastes like potato starch, sugarcane bagasse ash, wood sawdust, hemp, banana stem fiber, velvet tamarind

1 Instituto Tecnológico Metropolitano, ITM. Medellín, Colombia.

Autor de correspondencia: Vargas Isaza, C.A. (Carlos Andrés): Campus Fraternidad, calle 54A No. 30 - 01, Barrio Boston, Medellín, Colombia. Correo electrónico: carlosandres.vargasisaza@gmail.com
Historia del artículo:

Artículo recibido: 20-XI-2017/ Aprobado: 30-V-2019

Disponible online: 3 de julio de 2019

Discusión abierta hasta marzo de 2021 
seed shell, rice husk ash, silica from rice husk ash, coir fiber, pineapple leaf fiber, marble sludge, palm oil ash. The composition evaluation for each filler and methods of obtaining and treatments were evaluated. In addition, the rubber compounding and vulcanization, as well as the physical, chemical, thermal and mechanical properties were analysed.

Keywords: Natural rubber, agroindustrial wastes, reinforcement, carbon black, silica.

\section{Revisão - Comportamento físico-químico de compostos de borracha natural aos resíduos aditivos agroindustrial como enchimentos de reforço}

\section{Resumo}

Este trabalho apresenta uma revisão focada em compósitos de borracha natural reforçados com enchimentos obtidos de resíduos agroindustriais como amido de batata, cinza de bagaço de cana-de-açúcar, serradura de madeira, cânhamo, fibra de caule de banana, casca de sementes de tamarindo de veludo, cinza de casca de arroz, sílica de cinza de casca de arroz, coira fibra, fibra de abacaxi, lodo de mármore, cinzas de óleo de palma. A avaliação da composição para cada enchimento e métodos de obtenção e tratamentos foram avaliadas. Além disso, foram analisados os compostos de borracha e vulcanização, bem como as propriedades físicas, químicas, térmicas e mecânicas.

Palavras-chave: Borracha natural, resíduos agroindustriais, reforço, negro de carbono, sílica.

\section{Introducción}

Los residuos industriales y agroindustriales están ocasionando un problema ambiental evidente a nivel mundial, debido a la gran cantidad producida, la cual no tiene una disposición final adecuada, siendo una gran fuente de contaminación. En particular un estudio hecho por la Cámara de Comercio de la India indica que entre el 60 y $70 \%$ de los desechos agroindustriales son descargados al ambiente sin ningún tipo de tratamiento y solo el restante se emplea para la digestión anaeróbica en regiones como África, Europa del este, América latina y Asia (excepto Japón) (Eastern Research Group, TetraTech Consulting Group and Federation of Indian Chambers of Commerce and Industry, 2011).

La Tabla 1 muestra datos estadísticos del gran volumen de desechos agroindustriales producidos en diferentes países del mundo (Maiti et al., 2016), que evidencia la gran problemática mundial relati- va al manejo de estos, esta información es mostrada de acuerdo a lo reportado por diferentes autores y recopilada en el trabajo publicado por Maiti y colaboradores en el año 2016. Los costos tan altos que ocasionan a la industria la disposición de este tipo de materiales, ha hecho que se realicen muchas investigaciones en busca de mitigar el impacto y aumentar el aprovechamiento de estos en aplicaciones para la producción de bioetanol (Domínguez-Bocanegra, Torres-Muñoz and López, 2015), butanol (Maiti et al., 2016), digestión anaeróbica (Zahan, Othman and Muster, 2017), carbonización hidrotérmica (Verónica Benavente, Calabuig and Fullana, 2015), pirólisis (Fernandez et al., 2016), entre otras.

Se busca entonces poder disponer tanto de los residuos que generan alto volumen y por ende mayor dificultad de disposición y los que generan poco volumen, pero generan un alto impacto ambiental. A pesar de las aplicaciones que se han implementado 
en los últimos años para reutilizar estos residuos, la gran cantidad de estos motiva su uso en otras aplicaciones, donde su función como cargas de refuerzo en materiales compuestos en matrices poliméricas ha comenzado a implementarse (Santos, Silva and Alves, 2017; Yeșilay, Çakı and Ergun, 2017; Guzmán and Ruiz, 2011; Ferreira-Leitão et al., 2010).

TABLA 1. INFORMACIÓN RECOPILADA SOBRE LA PRODUCCIÓN DE DESECHOS AGROINDUSTRIALES EN DIFERENTES PARTES DEL MUNDO.

(MAITI ET AL., 2016; GONZALEZ, 2018)

\begin{tabular}{|c|c|c|c|}
\hline Año & $\begin{array}{c}\text { País/ } \\
\text { Continente }\end{array}$ & $\begin{array}{c}\text { Residuos agro- } \\
\text { industriales } \\
\text { producidos (t * } \\
1000)\end{array}$ & Referencias \\
\hline 2012 & Colombia & 71.944 & $\begin{array}{c}\text { (Gonzalez, } \\
\text { 2018) }\end{array}$ \\
\hline 2007 & $\begin{array}{l}\text { Nueva } \\
\text { Zelanda }\end{array}$ & 150 & $\begin{array}{c}\text { (Ajila et al., } \\
\text { 2012) }\end{array}$ \\
\hline 2007 & Bélgica & 1150 & \\
\hline 2007 & $\begin{array}{l}\text { República } \\
\text { Checa }\end{array}$ & 460 & \\
\hline 2007 & Finlandia & 860 & \\
\hline 2007 & Islandia & 50 & \\
\hline 2007 & Italia & 60.107 & \\
\hline 2007 & Holanda & 2390 & \\
\hline 2007 & Noruega & 160 & \\
\hline 2007 & Eslovaquia & 4490 & \\
\hline 2003 & Bulgaria & 50 & \\
\hline 1999 & Reino Unido & 84.000 & \\
\hline 1990 & Austria & 880 & \\
\hline 2007 & Francia & 400 & \\
\hline 2013 & Brasil & 324.788 & $\begin{array}{c}\text { (Virmond et } \\
\text { al., 2013) }\end{array}$ \\
\hline 2013 & Ucrania & 48.226 & \\
\hline 2003 & Dinamarca & 369 & $\begin{array}{c}\text { (McPhail, } \\
\text { Cigolotti } \\
\text { and Moreno, } \\
\text { 2012) }\end{array}$ \\
\hline 2009 & Australia & 112.000 & $\begin{array}{l}\text { (Nigam and } \\
\text { Pandey, } \\
\text { 2009) }\end{array}$ \\
\hline 2009 & China & 1120.000 & \\
\hline 2009 & India & 672.000 & \\
\hline 2007 & Japón & 90.430 & \\
\hline 2009 & Norteamérica & 1456.000 & \\
\hline
\end{tabular}

De acuerdo con lo anterior, se ha encontrado que los residuos posindustriales son utilizados como refuerzos al ser adicionados en matrices de caucho; en muchos casos adicionándolos en caucho natural; material que tiene propiedades tecnológicas interesantes, donde se puede resaltar su rendimiento mecánico, además de su carácter natural que lo hace más amigable con el medio ambiente con respecto a los cauchos sintéticos que son obtenidos generalmente de recursos no renovables como lo es el petróleo. Debido a lo anterior, las mezclas de cacho natural con residuos posindustriales han sido objeto de investigaciones durante las últimas décadas. La mayoría de las industrias del sector cauchero utilizan principalmente dos tipos de cargas comerciales, las cuales son el negro de humo y sílice (Posada-Correa et al., 2014; Patnaik and Brown, 2010; Pongdong et al., 2015; Ahmed et al., 2013b; Kaewasakul, 2013). La primera carga es utilizada para la fabricación de artículos en tonalidades oscuras y la segunda en artículos tanto oscuros como blancos o de colores de acuerdo a la necesidad técnica del producto, ya que las dos cargas poseen características físicas y químicas diferentes además de la diferencia del color. Como alternativa al uso de las cargas comerciales descritas anteriormente, se busca la sustitución de dichas cargas por residuos obtenidos en los diferentes procesos agroindustriales que generan en muchos casos impactos ambientales negativos, logrando de esta manera la incorporación de nuevas cargas de residuos industriales y agroindustriales al caucho natural, obteniendo mejoras en su rendimiento tecnológico y comportamiento fisicomecánico.

Las Figuras 1 y 2 muestran un consolidado del número de investigaciones realizadas en los últimos 27 años para algunas de las cargas alternativas obtenidas a partir de desechos industriales y para las cargas comerciales más utilizadas respectivamente. Se observa que, si bien los desarrollos e investigaciones en caucho natural reforzados con negro de humo y sílice son superiores con respecto a los refuerzos a partir de residuos industriales, se observa un crecimiento en investigaciones con estos últimos. 


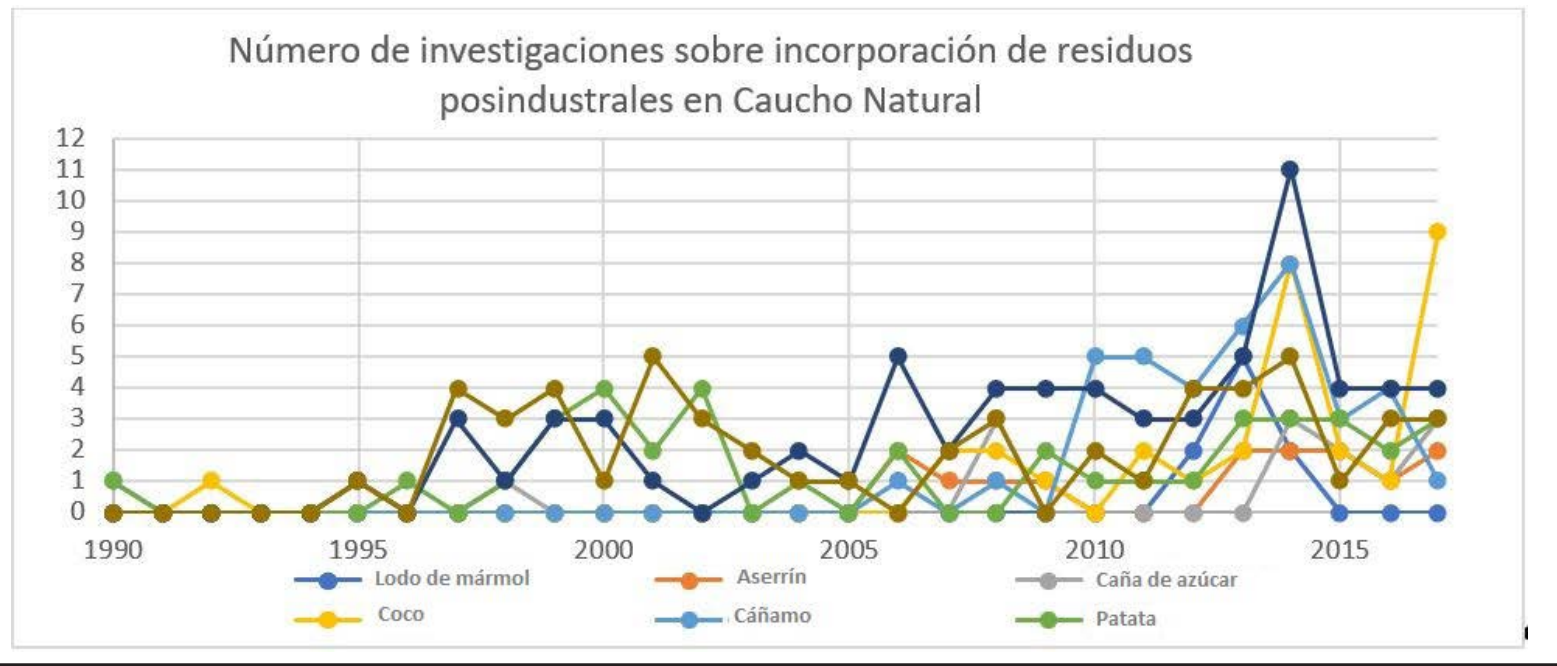

Figura 2. Número de investigaciones relacionadas con el uso de cargas comerciales en caucho natural (Scopus).

Número de investigaciones sobre incorporación de cargas comerciales en Caucho Natural

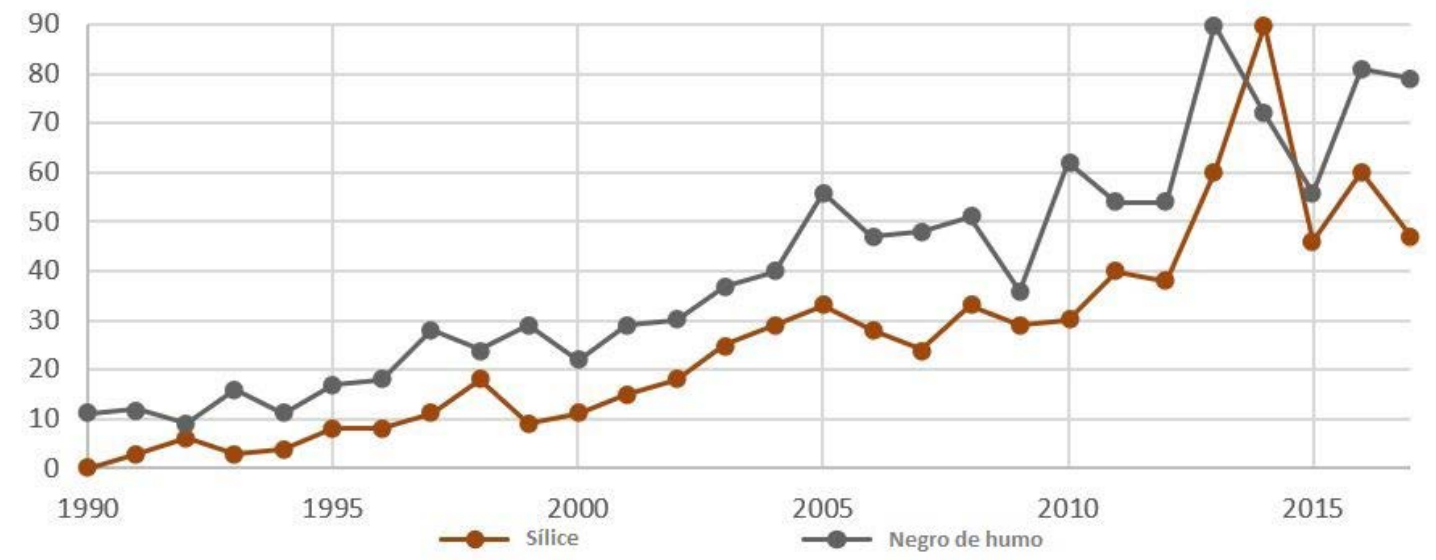

El propósito del presente trabajo es presentar una recopilación y análisis de los diferentes residuos agroindustriales empleados como refuerzos para compuestos de caucho natural. En este sentido, para cada residuo se discrimina su composición, método de obtención y el tratamiento que requieren previo a su incorporación en la matriz de caucho natural. Posteriormente, se establecen los diferentes procesos de incorporación de estos refuerzos en el caucho natural y finalmente, se realiza un análisis comparativo de propiedades de los diferentes compuestos de caucho natural obtenidos.

\section{Métodos de obtención y tratamiento de las cargas}

Un compuesto elastomérico consiste en la obtención de un nuevo material al mezclar un caucho con algún tipo de carga, buscando en todos los casos obtener mejores propiedades que el elastómero 
sin refuerzo. El material compuesto está constituido por una matriz o material ligante, en el caso del presente estudio caucho natural (NR), y además por un refuerzo, que en el caso de la presente revisión son residuos posindustriales y agroindustriales. Los refuerzos o cargas tienen como propósito aumentar las propiedades mecánicas, generar cambios superficiales y en la medida de lo posible generar disminución de costos (Imanah and Okieimen, 2003).

Los residuos que son estudiados en el presente trabajo y que son incorporados al caucho natural (NR) pueden ser obtenidos de diferentes formas; en muchos casos estas cargas se obtienen de residuos industriales que tienen una difícil disposición o en algunos casos en que dicha disposición es muy costosa. Algunas cargas utilizadas se pueden adicionar a la matriz sin ningún tratamiento previo, pero en muchos de casos, antes del proceso de mezclado deben ser sometidas a un tratamiento físico, químico, térmico, entre otros.(Hashim, Ismail and Rusli, 2017).
La interacción de la carga y el caucho natural depende de características como la composición química de la carga, la afinidad con el caucho y la química superficial; además de factores como el tamaño y la forma de las partículas que constituyen la carga y por lo tanto del área superficial de las mismas (Leblanc, 2002; Donnet, 1993; Urrego Yepes et al., 2018).

En la Tabla 2 se pueden observar los métodos de obtención de algunos de los residuos agroindustriales que han sido utilizados como cargas en el caucho natural; adicionalmente se observan los tratamientos previos a los que son sometidos dichos residuos antes de ser mezcladas e incorporadas en la matriz de caucho natural. Muchos de los tratamientos superficiales o de modificación química que se les hacen a las cargas mejoran notablemente la interacción con la matriz de caucho natural, esta afinidad mejora el rendimiento tecnológico de los compuestos.

TABLA 2. MÉTODO DE OBTENCIÓN Y TRATAMIENTO PARA CADA UNO DE LOS RESIDUOS AGROINDUSTRIALES EMPLEADOS COMO CARGAS

\begin{tabular}{|c|c|}
\hline CARGA & MÉTODO DE OBTENCIÓN Y TRATAMIENTO \\
\hline Almidón de patata & $\begin{array}{l}\text { En el caso de este residuo, se prepararon nano cristales de almidón de patata mediante la } \\
\text { hidrólisis de polvo de almidón de patata nativo usando ácido sulfúrico. En este proceso, se } \\
\text { mezclaron aproximadamente } 36 \mathrm{~g} \text { de gránulos de patata con } 250 \mathrm{ml} \mathrm{de} \mathrm{H}_{2} \mathrm{SO}_{4} 36 \mathrm{~N} \text { durante } \\
5 \text { días a } 40^{\circ} \mathrm{C} \text { y a una velocidad de agitación de } 100 \mathrm{rpm} \text {; esta suspensión se lavó con agua } \\
\text { destilada y entonces la dispersión se completó por un tratamiento ultrasónico durante } 10 \\
\text { minutos en un sonificador Branson B12. (Rajisha et al., 2014; Lecorre, Bras and Dufresne, 2012). }\end{array}$ \\
\hline $\begin{array}{c}\text { Bagazo de caña de } \\
\text { azúcar }\end{array}$ & $\begin{array}{l}\text { Las partículas de bagazo de caña de azúcar inicialmente fueron secadas y recocidas a } 80^{\circ} \mathrm{C} \\
\text { durante } 24 \text { horas, luego fueron tamizadas hasta la malla } 325 \text { (tamaños de partículas menores o } \\
\text { iguales a } 45 \text { micras) (Santos et al., 2014). }\end{array}$ \\
\hline Aserrín & $\begin{array}{l}\text { Para el caso del aserrín, este residuo fue utilizado sin ninguna modificación, pero generalmente } \\
\text { fue clasificado de acuerdo con su tamaño de partícula. Los autores que han trabajado con este } \\
\text { tipo de residuos definen una longitud de fibra crítica mínima por debajo de la cual las fibras no } \\
\text { actúan como agentes de refuerzo (Manaila et al., 2016). }\end{array}$ \\
\hline Cáñamo & $\begin{array}{l}\text { A partir de hojas de cáñamo se obtuvo material particulado de acuerdo con el siguiente } \\
\text { proceso: las hojas de cánamo fueron remojadas durante } 1 \text { semana en un recipiente de plástico } \\
\text { limpio, como consecuencia se genera un residuo verdoso que es posteriormente eliminado. Se } \\
\text { obtiene entonces una fibra blanquecina que es secada al aire durante algunos días y entonces } \\
\text { es pulverizada; finalmente el polvo obtenido es tamizado a través de un tamiz con un diámetro } \\
\text { de malla de } 212 \mathrm{~nm} \text { (Stelescu et al., 2014). }\end{array}$ \\
\hline
\end{tabular}




\begin{tabular}{|c|c|}
\hline $\begin{array}{l}\text { Vástago de } \\
\text { plátano }\end{array}$ & $\begin{array}{l}\text { Las fibras de vástago de plátano fueron tratadas inicialmente con } \mathrm{NaOH} \text { al } 4 \% \text { y con una solución } \\
\text { al } 2 \% \text { de } \mathrm{Na}_{2} \mathrm{SO}_{3} \text { durante } 24 \text { horas, luego estas fibras fueron lavadas con agua destilada y secadas } \\
\text { al sol durante } 48 \text { horas. Para eliminar cualquier traza de humedad, las fibras se secaron en un } \\
\text { horno a } 60^{\circ} \mathrm{C} \text { durante } 1 \text { hora (Ezema et al., 2014). }\end{array}$ \\
\hline $\begin{array}{l}\text { Cáscara de semilla } \\
\text { de tamarindo de } \\
\text { terciopelo }\end{array}$ & $\begin{array}{l}\text { Las semillas de tamarindo de terciopelo fueron secadas hasta masa constante en un horno a } \\
80^{\circ} \mathrm{C} \text { durante pocas horas. Las cáscaras secas se trituraron hasta obtener material particulado } \\
\text { fino. La muestra pulverizada se tamizó a través de un tamiz de malla con una abertura de } 200 \mathrm{~nm} \\
\text { (Okoh and Osabohien, 2014; Obasi, Okorocha and Orisakwe, 2013). }\end{array}$ \\
\hline Cascarilla de arroz & $\begin{array}{l}\text { Inicialmente la cascarilla de arroz fue molida hasta conseguir un polvo, luego se tamizó hasta } \\
\text { lograr tamaños de partícula con un diámetro promedio entre } 150-45 \text { micras. La densidad de la } \\
\text { cascarilla de arroz fue determinada por un método de desplazamiento de agua y su valor fue } \\
\text { de } 1.59 \mathrm{~g} / \mathrm{cm}^{3} \text {. La cascarilla de arroz se agitó en un vaso de precipitación con solución al } 5 \% \text { de } \\
\mathrm{NaOH} \text { por una hora a temperatura ambiente y fue secada en un horno a } 60^{\circ} \mathrm{C} \text { durante } 24 \text { horas, } \\
\text { luego fue sumergida en una solución de LNR (Liquid natural rubber) al } 10 \% \text { en tolueno. Después } \\
\text { se agitó la mezcla durante } 30 \text { minutos (a temperatura ambiente y entonces fue nuevamente } \\
\text { agitada en un baño sónico durante } 30 \text { minutos. La cascarilla de arroz recubierta con LNR fue } \\
\text { filtrada y se secó en un horno de vacío a } 60^{\circ} \mathrm{C} \text { durante } 24 \text { horas (Ahmad et al., 2012). }\end{array}$ \\
\hline $\begin{array}{l}\text { Sílice obtenida } \\
\text { a partir de la } \\
\text { cascarilla de arroz }\end{array}$ & $\begin{array}{l}\text { En este caso, la cascarilla de arroz fue lavada con agua para eliminar cualquier material extraño. } \\
\text { Posteriormente se preparó una solución de ácido clorhídrico } 0,4 \mathrm{M} \text { y luego se mezclaron } 100 \mathrm{~g} \\
\text { de cascarilla en } 1 \text { litro de solución ácida, entonces la mezcla fue calentada a } 100-105^{\circ} \mathrm{C} \text { durante } \\
30-45 \mathrm{~min} \text {. Después de la reacción, el ácido se eliminó completamente de la cáscara mediante } \\
\text { lavado con agua del grifo. Luego se secó en un horno a } 110^{\circ} \mathrm{C} \text { durante } 3-5 \mathrm{~h} \text {. La cascarilla tratada } \\
\text { se quemó en un horno eléctrico a } 600^{\circ} \mathrm{C} \text { durante } 6 \mathrm{~h} \text {; como resultado se obtuvo sílice en forma } \\
\text { de ceniza blanca (Ahmed, Nizami and Raza, 2013). }\end{array}$ \\
\hline Fibra de Coco & $\begin{array}{l}\text { La fibra de coco se obtuvo como resultado del procesamiento local en Kollam, India. Este residuo } \\
\text { tiene un diámetro promedio de } 100-400 \text { micras y una gravedad especifica de } 1.15 \text {. La Médula } \\
\text { de bonote (filamento extraído de la corteza del coco) y otros materiales indeseables fueron } \\
\text { separados. Luego las fibras fueron cortadas a unos } 10 \mathrm{~mm} \text { longitud, posteriormente se trataron } \\
\text { con hidróxido de sodio y carbonato de sodio. Las fibras se lavaron repetidamente con agua } \\
\text { y fueron secadas en el aire. Las fibras tratadas con hidróxido de sodio se mezclaron con una } \\
\text { solución de caucho natural líquido despolimerizado al } 6 \% \text { y } 1 \% \text {. (Geethamma et al., 1998, 2005). }\end{array}$ \\
\hline $\begin{array}{l}\text { Fibra de hoja de } \\
\text { piña }\end{array}$ & $\begin{array}{l}\text { La fibra de hoja de piña (PALF) fue separada de las hojas de piña por la novedosa técnica } \\
\text { de fresado. (Panyasart et al., 2014). La PALF se empapó en solución de } \mathrm{NaOH} \text { al } 10 \% \text { (w/v) a } \\
\text { temperatura ambiente durante } 30 \text { minutos. Luego, la fibra se lavó con agua destilada hasta } \\
\text { que el pH fue neutro, la fibra obtenida se denomina PALF tratada o TPALF. Luego la TPALF se } \\
\text { secó en un horno de aire caliente a } 80^{\circ} \mathrm{C} \text { durante } 24 \text { horas para eliminar toda el agua residual } \\
\text { (Yantaboot and Amornsakchai, 2017). }\end{array}$ \\
\hline Lodo de mármol & $\begin{array}{l}\text { El lodo de mármol (LM) fue secado en un horno de vacío a } 80^{\circ} \mathrm{C} \text { durante } 24 \text { horas y luego fue } \\
\text { pulverizado para conseguir un tamaño de partícula más fino. El LM de tierra pasó a través de un } \\
\text { tamiz para obtener cinco micro-tamaños diferentes tales como } 10,15,20,37 \text { y } 75 \mu \mathrm{m} \text { y con una } \\
\text { densidad de } 2,67 \mathrm{~g} / \mathrm{cm} 3 \text { (Ahmed et al., 2013a). }\end{array}$ \\
\hline $\begin{array}{c}\text { Ceniza de palma } \\
\text { de aceite }\end{array}$ & $\begin{array}{l}\text { La palma de aceite se seca en un horno de vació a } 80^{\circ} \mathrm{C} \text { durante } 24 \text { horas para eliminar la } \\
\text { humedad. Luego fue tamizada empleando una malla de } 75 \text { micras para separar los residuos } \\
\text { grandes y los no quemados (Ooi, Ismail and Bakar, 2013a). }\end{array}$ \\
\hline
\end{tabular}


Luego de conocer el proceso de obtención y tratamiento de las cargas se pueden analizar sus respectivas características y composición, que le confieren a los materiales un determinado comportamiento frente a su procesabilidad y propiedades finales del compuesto.

La Tabla 3 y Tabla 4 permite analizar información sobre la composición de los residuos empleados como cargas, estos datos pueden brindar información de cómo se comportarán los refuerzos al momento de incorporarlo al caucho natural.

\section{Incorporación de cargas}

La adición de cargas reforzantes al caucho natural y la interacción de los materiales puede gene- rar o no una mejora en las propiedades fisicoquímicas del material compuesto, ampliando de esta manera el abanico de usos. La adición de las cargas comerciales como el negro de humo, por ejemplo, genera una mejora notable en propiedades como la resistencia a la abrasión, al desgarre, a la fatiga, a la fisura por flexión y al desgaste, también mejora el procesamiento, la dureza del material, su elongación y elasticidad; se espera entonces que algunas cargas obtenidas como residuos agroindustriales puedan mejorar algunas de las propiedades que las cargas comerciales potencializan al ser adicionados en una matriz de caucho natural (Martínez, Murillo and García, 2013; Rattanasom and Prasertsri, 2012).

TABLA 3. COMPOSICIÓN QUÍMICA DE LAS CARGAS AGROINDUSTRIALES QUE HAN SIDO INCORPORADAS EN CAUCHO NATURAL

(JARAMILLO PINEDA, GÓMEZ GARCÍA AND ALZATE, 2012; LÓPEZ-MIRANDA ET AL., 2009; MOHAMMED ET AL., 2015; GONZÁLEZ-VELANDIA ET AL., 2016)

\begin{tabular}{|c|c|c|c|c|c|}
\hline \multicolumn{6}{|c|}{ COMPOSICIÓN QUÍMICA DE LAS CARGAS } \\
\hline Carga residual & Celulosa \% & Hemicelulosa \% & Lignina \% & Xilano \% & Pectinas \% \\
\hline Bagazo de caña de azúcar & 34.5 & 22.4 & 18.9 & 20.7 & 0 \\
\hline Aserrín & 46.4 & 8.8 & 29.4 & 0 & 0 \\
\hline Cáñamo & 68 & 15 & 10 & 0 & 0 \\
\hline Vástago de plátano & 55.65 & 14 & 11.58 & 0 & 0 \\
\hline Cascarilla de arroz & $35-45$ & $19-25$ & 20 & 0 & 0 \\
\hline Fibra de coco & $36-43$ & $0.15-0.25$ & $41-45$ & 0 & $3-4$ \\
\hline Fibra de hoja de piña & $11-45$ & $14-50$ & $10-30$ & 0 & 0 \\
\hline Ceniza de palma de aceite & 0 & 18.8 & 9.45 & 0 & 0 \\
\hline
\end{tabular}

TABLA 4. COMPOSICIONES QUÍMICAS DE OTRAS CARGAS AGROINDUSTRIALES (NATURALEZA QUÍMICA DIFERENTE A LAS CARGAS REPORTADAS EN LA TABLA 3)

(RODOLFO RUIZ POSADA, JULIO CÉSAR RODRÍGUEZ GALVIS AND LUIS O. HERNÁNDEZ, 2014; SANTOS, VILLEGAS AND BETANCOURT, 2012)

\begin{tabular}{|c|c|c|c|c|}
\hline \multirow{2}{*}{ Carga residual } & \multicolumn{4}{|c|}{ Composición } \\
\hline \multirow{2}{*}{ Almidón de patata } & Amilosa (\%) & Amilopectina (\%) & & \\
\cline { 2 - 5 } & 20 & 80 & Carbohidratos \% & Fibra\% \\
\hline $\begin{array}{c}\text { Cáscara de semilla de tamarin- } \\
\text { do de terciopelo }\end{array}$ & Proteínas \% & Grasas \% & 62 & 5 \\
\cline { 2 - 5 } & 2.8 & 0.6 & $\mathbf{A l} \%$ & $\mathbf{S i O}_{\mathbf{2}} \%$ \\
\hline \multirow{2}{*}{ Lodo de mármol } & $\mathbf{C a C O}_{\mathbf{3}} \%$ & $\mathbf{F e} \%$ & 0.10 & 1.02 \\
\cline { 2 - 5 } & 95 & 0.038 & & \\
\hline
\end{tabular}


Las cargas comerciales como el negro de humo traen consigo efectos negativos en el medio ambiente y en la salud de las personas que están expuestas a sus partículas, ya que durante su producción se generan impurezas en la atmosfera que finalmente generan polución en el aire y daños en las vías respiratorias de las personas. Por lo tanto, es importante estudiar diferentes cargas provenientes de residuos agroindustriales que en lugar de generar un efecto nocivo en el medio ambiente y en la salud de las personas, pueden mitigar la generación de contaminantes y desechos dispuestos en rellenos sanitarios, mejorando algunas propiedades físicas de los compuestos de matriz elastomérica a un menor costo comparándolos con los costos de los compuestos elastoméricos elaborados con cargas comerciales (Goldberg, 1985; Donnet, 1993; Sorahan and Harrington, 2007; WANG et al., 2002). Sin embargo, y teniendo presente el uso masivo del negro de humo como refuerzo de caucho natural, es importante resaltar que no siempre el uso de negro de humo significa una mejora de todas las propiedades simultáneamente, es decir, algunas propiedades decrecen con la adición del negro de humo mientras otra aumentan y es por esto que en algunos casos se deben manejar pequeños rangos del contenido del refuerzo en la mezcla de caucho (AL-nesrawy et al., 2014; Fu et al., 2013; Patnaik and Brown, 2010). Otra carga comercial muy usada en los compuestos elastoméricos es la sílice que actúa como un excelente refuerzo y que proporciona (además de algunas de las propiedades que el negro de humo le aporta al caucho natural) una combinación única de resistencia al desgarre, resistencia al envejecimiento y buenas propiedades de adhesión (P, TE and SP, 2016).

Durante el proceso de mezclado se pueden presentar diferentes situaciones que afectan la uniformidad en las propiedades del compuesto de caucho natural. La sílice por ejemplo tiende a formar enlaces de hidrógeno y no poseen una adecuada interacción con el caucho natural, es por esto que se deben implementar agentes de acoplamiento que reaccionen químicamente con la carga y con el cau- cho durante el proceso de mezclado y vulcanización (P, TE and SP, 2016).

La incorporación de las cargas en el caucho natural se puede realizar empleando diferentes métodos de procesamiento, en la mayoría de los casos se emplean dos tipos de mezcladores conocidos como mezcladores internos y mezcladores abiertos. La dispersión y distribución de las cargas en la matriz de caucho natural depende directamente del mezclador o equipo de proceso empleado, además del esquema de mezclado. Adicionalmente la interacción de la carga con el caucho natural va a depender de la composición química de la carga y su afinidad con el caucho, es por esto que en muchos casos las cargas deben ser funcionalizadas o tratadas física y químicamente para mejorar dicha interacción (WHITE, 1994; Pinchuk et al., 2001; Akinlabi et al., 2006; ASTM International, 2013; Urrego Yepes et al., 2017).

De acuerdo con lo anterior, cuando se van emplear cargas reforzantes en el caucho natural se deben tener en cuenta la naturaleza de las cargas, la necesidad de realizar un tratamiento previo de las cargas para mejorar el tamaño, forma e interacción química con el caucho natural, pero adicionalmente se deben elegir adecuadamente los procesos de mezclado para asegurar de esta manera la mejor incorporación posible de la carga en el caucho natural. Es entonces cuando se definen los esquemas de mezclado y los equipos de proceso. Los mezcladores internos, como el mezclador tipo Banbury, permiten lograr altas velocidades de cizallas, fenómeno que generará una mejor dispersión de las cargas en la matriz de caucho natural, mientras un molino abierto de rodillos no posee la misma capacidad, por lo tanto, los tiempos de mezcla deberían ser diferentes dependiendo el equipo que se va a utilizar (ASTM International, 2013; Akinlabi et al., 2006; Urrego Yepes et al., 2018).

A continuación, se describen algunos procesos de mezclado e incorporación de las cargas de residuos agroindustriales en matrices de caucho natural, especificando en algunos casos los parámetros de proceso, que finalmente influirán en la 
homogeneidad de la mezcla y por lo tanto en las propiedades finales de los compuestos:

Almidón de patata: La suspensión acuosa de nano cristales de almidón de patata y látex de caucho natural se mezcló en varias proporciones a temperatura ambiente usando un agitador mecánico durante 15 minutos para asegurar una dispersión uniforme. Luego se mantuvo la mezcla 1 hora para su homogeneización y la sedimentación de impurezas. Posteriormente se agitó la mezcla usando vacío en un roto evaporador durante 10 minutos, con el fin de desgasificar y evitar la formación de burbujas durante la evaporación del agua. Se formaron entonces películas con un espesor uniforme mediante vaciado en un molde de vidrio y se evaporaron a $40^{\circ} \mathrm{C}$ en un horno en lapso de tiempo entre 4 a 6 horas, con un calentamiento posterior a $60^{\circ} \mathrm{C}$ bajo vacío por 2 horas. Las películas se acondicionaron a temperatura ambiente en un desecador con $\mathrm{P}_{2} \mathrm{O}_{5}$ (Rajisha et al., 2014).

Ceniza de bagazo de caña de azúcar (SBA, por sus siglas en inglés): En este trabajo se elaboraron compuestos con diferentes cantidades de SBA, las cuales varían de 0 hasta $50 \mathrm{phr}$, el proceso de masticación del caucho natural, fue llevado a cabo en un mezclador de dos rodillos, donde se adicionaron diferentes ingredientes para garantizar la distribución uniforme de los aditivos, este proceso se realizó durante un tiempo entre 20 a 30 minutos. Posteriormente, las mezclas fueron llevadas al proceso de prensado para su vulcanización a una temperatura de 150 a $160^{\circ} \mathrm{C}$ (Santos et al., 2014; Kanking et al., 2012).

Aserrín: Los compuestos de caucho natural con aserrín fueron elaborados en un molino de dos rodillos calentado eléctricamente, donde fue homogenizada y laminada la mezcla por un tiempo entre 8 a 14 minutos, la razón de fricción de los rodillos fue de 1: 1.1, y la temperatura del proceso fue establecida entre 25 y $50^{\circ} \mathrm{C}$. Las mezclas luego fueron vulcanizadas en una prensa hidráulica con una presión de $150 \mathrm{MPa}$ y a una temperatura de $110^{\circ} \mathrm{C}(\mathrm{Ma}$ naila et al., 2016).
Cáñamo: Para el mezclado de la carga con el caucho natural se empleó un molino de dos rodillos, se emplearon formulaciones donde la carga varía desde 0 hasta $70 \mathrm{phr}$; la temperatura del proceso se mantuvo por debajo de los $80^{\circ} \mathrm{C}$ y el curado de los compuestos se realizó por compresión en una prensa a temperaturas entre 110 y $180^{\circ} \mathrm{C}$ (Stelescu et al., 2014; Osabohien and Egboh, 2008).

Vástago de plátano: Las mezclas del caucho natural fueron elaboradas en un molino de tres rodillos durante aproximadamente 30 minutos, luego se colocaron las fibras del tallo entre dos capas de caucho y entonces se recubrieron con láminas de PET, luego se moldearon por compresión en una prensa hidráulica durante aproximadamente $5 \mathrm{mi}$ nutos a $150{ }^{\circ} \mathrm{C}$ con una presión de $115 \mathrm{~kg} / \mathrm{cm}^{2}$ (Ezema et al., 2014).

Cáscara de semilla de tamarindo de terciopelo: La formulación de los compuestos varió entre 0 y 70 phr de carga, el caucho natural y los aditivos se mezclaron en un molino de dos rodillos a $80^{\circ} \mathrm{C}$. El proceso de curado se realizó en una prensa calentada por vapor con una presión de $150 \mathrm{~kg} / \mathrm{cm}^{2}$, a una temperatura de $185^{\circ} \mathrm{C}$ (Okoh and Osabohien, 2014).

Cascarilla de arroz: Se prepararon inicialmente mezclas de caucho natural (60\%) con polietileno de alta densidad (40\%) en un mezclador cerrado a $135^{\circ} \mathrm{C}$ durante 10 minutos a una velocidad de $50 \mathrm{rpm}$; luego el compuesto fue granulado. Las mezclas de cascarilla de arroz con caucho natural y polietileno de alta densidad (con variaciones de 10\% a $30 \%$ en peso de la cascarilla de arroz) se mezclaron en estado fundido a $135^{\circ} \mathrm{C}$ durante 13 minutos con una velocidad de $45 \mathrm{rpm}$. Finalmente los compuestos se prensaron en caliente en hojas de 1 y $3 \mathrm{~mm}$ (Ahmad et al., 2012).

Sílice obtenida a partir de la cascarilla de arroz: En uno de los estudios realizados con este tipo de cargas, se empleó un molino cerrado para realizar la incorporación de las ceniza de cascarilla de arroz en caucho natural epoxidado. Las condiciones fueron de $80^{\circ} \mathrm{C}$ y a una velocidad de rotación de 40rpm; en este estudio se emplearon agentes de 
acople para mejorar la interacción del residuo con el caucho natural epoxidado (Pongdong et al., 2015). La adición en caucho natural de la ceniza de cascarilla de arroz también ha sido estudiada en conjunto con otro tipo de residuos como por ejemplo ceniza proveniente del bagazo de la caña de azúcar y cenizas provenientes de aceite de palma, en este caso, los componentes de la mezcla incluyendo cada tipo de ceniza fueron adicionados en un mezclador interno mientras que el sistema de vulcanización fue adicionado en un molino abierto de dos rodillos (Pinpat, Keawwattana and Tangbunsuk, 2017). De igual manera, la ceniza de cascarilla de arroz también ha sido mezclada con sílice comercial y lodo de mármol antes de ser incorporada en el caucho natural, en este caso el proceso de mezclado fue llevado a cabo en un molino abierto de rodillos (Ahmed, Nizami and Raza, 2013). Finalmente, en otro estudio se adicionó la ceniza de cascarilla de arroz en el caucho natural con el propósito de evaluar la función de óxidos metálicos en la cinética de la reacción de vulcanización con azufre. La mezcla de los ingredientes se desarrolló en un molino abierto de rodillos a una temperatura de $70^{\circ} \mathrm{C}$ de acuerdo a la norma ASTM D 3182 (Da Costa et al., 2003b).

Fibra de coco: Las formulaciones de los materiales compuestos contienen entre 10 y $60 \mathrm{phr}$ de fibra de coco, el mezclado se realiza en un molino de dos rodillos cuya apertura entre ellos es de $1,25 \mathrm{~mm}$, las fibras se incorporan al final del proceso de mezclado teniendo en cuenta la alineación del sentido en el compuesto. El proceso de curado fue establecido a una temperatura de $150^{\circ} \mathrm{C}$ (Geethamma et al., 1998, 2005).

Fibra de hoja de piña: Se realizó inicialmente una masticación del caucho (durante 2, 4, 8 y 16 minutos). Los compuestos se prepararon en un molino de dos rodillos formando láminas y luego se fueron vulcanizados en un sistema hidráulico a 10MPa y $150^{\circ} \mathrm{C}$.(Yantaboot and Amornsakchai, 2017). En otro trabajo se prepararon los compuestos de caucho y fibra de hoja de piña en dos etapas, en la primera se utilizó un molino de dos rodillos a una velo- cidad de $50 \mathrm{rpm}$ y a una temperatura de $40^{\circ} \mathrm{C}$ para mezclar caucho natural con caucho nitrilo y con las fibras de hoja de piña; luego se agregó secuencialmente los demás componentes, finalmente se moldeó por compresión la mezcla a $150^{\circ} \mathrm{C}$ para obtener láminas de $1 \mathrm{~mm}$ de espesor.(Panyasart et al., 2014).

Lodo de mármol: El mezclado se realizó de acuerdo con la norma ASTM 3182 en un molino de dos rodillos, se masticó el caucho y luego se agregó la carga que varió entre 20 y 100phr en la formulación donde la carga es solamente lodo de mármol, para este caso las características de vulcanización se midieron a una temperatura de $140^{\circ} \mathrm{C}$ durante 20 minutos. De otra manera se realizaron compuestos híbridos con sílice, donde las proporciones de lodo de mármol y sílice fueron diferentes, donde cuya formulación es de $60 \mathrm{phr}$ (Ahmed et al., 2013a; Iqbal et al., 2016; Ahmed, Nizami and Raza, 2013).

Ceniza de palma de aceite: El desarrollo de mezclas con ceniza de palma de aceite se realiza en un molino de dos rodillos durante aproximadamente 20 minutos, las características de vulcanización se miden según la ISO 3417 a $150^{\circ} \mathrm{C}$, misma temperatura a la que se realiza el moldeo por compresión (Ooi, Ismail and Bakar, 2013a; Ooi, Ismail and Abu Bakar, 2014).

\section{Análisis comparativo, desempeño y propiedades de los compuestos de caucho natural mezclados con residuos agroindustriales}

$\mathrm{Al}$ analizar en la literatura los diferentes compuestos elaborados a partir de una mezcla de caucho natural con residuos provenientes de procesos agroindustriales, se puede establecer un procedimiento general que puede ayudar a seguir un paso a paso para la adecuada incorporación y elaboración de los materiales compuestos de caucho natural reforzados con residuos posindustriales:

Inicialmente se define si es necesario o no realizar un tratamiento físico o químico de los residuos, 
por ejemplo, en algunos casos es necesario emplear procesos de conminución de tamaño y en otros procesos de neutralización con ácidos o bases de acuerdo con la naturaleza de los residuos; en la mayoría de los casos los residuos deben ser secados antes de incorporarlos en la matriz elastomérica. Para definir el tratamiento que se le debe aplicar a las cargas, se debe conocer inicialmente sus características fisicoquímicas, algunas de las técnicas de caracterización empleadas para este propósito han sido espectroscopía de infrarrojo por transformada de Fourier (FTIR) (Fu et al., 2013; Iqbal et al., 2016; Ooi, Ismail and Abu Bakar, 2013), difracción de rayos x (XRD) (Iqbal et al., 2016; Rajisha et al., 2014), fluorescencia de rayos x (XRF) (Ahmed, Nizami and Raza, 2013; Ooi, Ismail and Bakar, 2013a), espectroscopía de emisión de plasma de acoplamiento inductivo (ICPES) (Da Costa et al., 2003a; b), microscopía electrónica de barrido (SEM) (Ahmad et al., 2012; Ezema et al., 2014; Fu et al., 2013; Hariwongsanupab et al., 2017; Iqbal et al., 2016; Ooi, Ismail and Abu Bakar, 2013), microscopía electrónica de transmisión (TEM) (Fu et al., 2013; Iqbal et al., 2016; Rajisha et al., 2014), área superficial mediante el método BET (Brunauer, Emmett and Teller) (Ahmed et al., 2013a; Da Costa et al., 2003a; b) y análisis térmico por calorimetría diferencial de barrido (DSC) y mediante análisis termogravimétrico (TGA) (Ahmed, Nizami and Raza, 2013; Fernandez et al., 2016; Panyasart et al., 2014)(ver Tabla 5).

Antes del proceso de mezclado del caucho natural con los residuos agroindustriales, se deben establecer el resto de ingredientes que harán parte de la formulación de los compuestos de caucho natural. Los ingredientes se pueden agrupar en sistemas, por ejemplo, se debe definir el sistema de vulcanización (azufre, acelerantes, peróxidos), el sistema de, los sistemas de protección (antioxidantes, antiozonantes) y los ayudantes de proceso, entre otros.

Dependiendo de la forma y tamaño de los residuos se establece el proceso de mezclado con el caucho natural, se emplean entonces diferentes equipos y esquemas para la incorporación de los mismos. En algunos casos se pueden emplear mezcladores cerrados como por ejemplo mezcladores tipo Banbury y reómetros de torque, en otros casos se emplean mezcladores abiertos como por ejemplo molinos abiertos o de rodillos; en este caso se debe tener claro que la incorporación de los residuos en el caucho natural será diferente, esto se debe a las diferentes velocidades de cizalla que se generan en los dos equipos de proceso, siendo mayores las velocidades de cizalla generadas en el mezclador interno, por lo que se espera una mejor dispersión y distribución de los residuos cuando se emplea este tipo de equipos (WHITE, 1994; Pinchuk et al., 2001; Akinlabi et al., 2006; Dimier, Vergnes and Vincent, 2004; ASTM International, 2013; Urrego Yepes et al., 2018).

Los residuos agroindustriales pueden generar cambios significativos en el proceso de vulcanización de los compuestos de caucho natural. La naturaleza ácida o básica de los residuos genera cambios en los tiempos empleados para la vulcanización del caucho, por ejemplo el tiempo que se demora para comenzar la reacción de vulcanización o tiempo "scorch" $\left(\mathrm{t}_{\text {scorch }}\right)$ puede ser alterado por la incorporación de los residuos, al mismo tiempo que puede ser alterado el tiempo óptimo de vulcanización $\left(\mathrm{t}_{100}\right)$; el tiempo necesario para alcanzar el $90 \%\left(\mathrm{t}_{90}\right)$ de la vulcanización es un parámetro empleado en el sector cauchero, por lo que es común en algunos trabajos encontrar reportado el $t_{90}$ en lugar del $t_{100}$ (Urrego Yepes et al., 2018; Ravichandran and Natchimuthu, 2005a; b; Cardona, Velásquez and Giraldo, 2017). Los torques máximo $\left(\mathrm{M}_{\mathrm{H}}\right)$ y mínimo $\left(\mathrm{M}_{\mathrm{L}}\right)$ obtenidos mediante la reometría de vulcanización también pueden verse afectados por la incorporación de los residuos posindustriales, esto se debe al aumento en la viscosidad del caucho natural al incorporar los residuos, efecto que se verá reflejado en el aumento del torque mínimo $\left(\mathrm{M}_{\mathrm{L}}\right)$ o un aumento en el torque máximo $\left(\mathrm{M}_{\mathrm{H}}\right)$ como resultado del efecto reforzante de los residuos, representando un primer acercamiento a las propiedades mecánicas de los compuestos. 
Finalmente, los compuestos de caucho natural reforzados con residuos posindustriales pueden ser evaluados mediante el análisis de sus propiedades mecánicas, como por ejemplo la resistencia a la tensión, al desgarre, a la compresión, dureza, entre otras. De acuerdo con el rendimiento mecánico de los compuestos, estos pueden ser empleados en diferentes aplicaciones, obteniéndose con está la posibilidad de fabricar nuevos productos empleando residuos que su disposición final significa una problemática ambiental.
En la Tabla 5 se resumen los compuestos de caucho natural desarrollados con diversos tipos de residuos posindustriales con la respectiva caracterización en las fibras y en los compuestos de caucho natural obtenidos.

De acuerdo con la información presentada en la Tabla 5, puede establecerse que para evaluar la morfología y tamaños de los residuos posindustriales que son mezclados con caucho natural, la microscopía electrónica de barrido (SEM) es la técnica empleada en mayor proporción, comparada con la microscopia electrónica de transmisión (TEM).

\begin{tabular}{|c|c|c|c|c|}
\hline Tipo residuo & $\begin{array}{l}\text { Caracterización } \\
\text { de residuo }\end{array}$ & $\begin{array}{l}\text { Proceso de } \\
\text { mezclado }\end{array}$ & Propiedades del compuesto & Referencia \\
\hline $\begin{array}{l}\text { Almidón de } \\
\text { patata }\end{array}$ & XRD, TEM, & $\begin{array}{l}\text { Agitador } \\
\text { mecánico }\end{array}$ & Tensión, hinchamiento, SEM, XRD & $\begin{array}{l}\text { (Rajisha et al., } \\
\text { 2014) }\end{array}$ \\
\hline $\begin{array}{l}\text { Ceniza de } \\
\text { bagazo }\end{array}$ & $\begin{array}{l}\text { FTIR, XRF, XRD, } \\
\text { SEM }\end{array}$ & $\begin{array}{l}\text { Molino de dos } \\
\text { rodillos }\end{array}$ & $\begin{array}{l}\text { Tensión, dureza, compresión set, } \\
\text { hinchamiento }\end{array}$ & $\begin{array}{l}\text { (Kanking et al., } \\
\text { 2012) }\end{array}$ \\
\hline $\begin{array}{l}\text { Ceniza de } \\
\text { bagazo caña } \\
\text { de azúcar }\end{array}$ & SEM, EDS & $\begin{array}{l}\text { Cámara de } \\
\text { mezclado abierta }\end{array}$ & $\begin{array}{l}\text { Características de curado, tensión, } \\
\text { abrasión, DMA, TGA, DSC, SEM }\end{array}$ & $\begin{array}{l}\text { (Santos et al., } \\
\text { 2014) }\end{array}$ \\
\hline Aserrín & & $\begin{array}{l}\text { Rodillo con control } \\
\text { calefacción }\end{array}$ & $\begin{array}{l}\text { Tensión, dureza, resistencia al } \\
\text { rasgado, fracción gel y densidad } \\
\text { de entrecruzamiento, absorción de } \\
\text { humedad, interacción fibra-caucho, } \\
\text { FTIR, SEM }\end{array}$ & $\begin{array}{l}\text { (Manaila et al., } \\
\text { 2016) }\end{array}$ \\
\hline \multirow[b]{2}{*}{ Cáñamo } & $\begin{array}{l}\text { Propiedades } \\
\text { fisicoquímicas }\end{array}$ & $\begin{array}{l}\text { Molino de dos } \\
\text { rodillos }\end{array}$ & $\begin{array}{l}\text { Características de curado, tensión, } \\
\text { dureza, abrasión }\end{array}$ & $\begin{array}{l}\text { (Osabohien and } \\
\text { Egboh, 2008) }\end{array}$ \\
\hline & & $\begin{array}{l}\text { Rodillo con control } \\
\text { calefacción }\end{array}$ & $\begin{array}{l}\text { Tensión, dureza, contenido de gel, } \\
\text { densidad de entrecruzamiento, } \\
\text { absorción de agua, FTIR }\end{array}$ & $\begin{array}{l}\text { (Stelescu et al., } \\
\text { 2014) }\end{array}$ \\
\hline $\begin{array}{l}\text { Vástago de } \\
\text { plátano }\end{array}$ & & $\begin{array}{l}\text { Molino de mezcla } \\
\text { de } 3 \text { rodillos }\end{array}$ & Tensión, SEM & $\begin{array}{l}\text { (Ezema et al., } \\
\text { 2014) }\end{array}$ \\
\hline $\begin{array}{l}\text { Cáscara de } \\
\text { semilla de } \\
\text { tamarindo }\end{array}$ & $\begin{array}{l}\text { Propiedades } \\
\text { fisicoquímicas }\end{array}$ & $\begin{array}{l}\text { Molino de dos } \\
\text { rodillos }\end{array}$ & $\begin{array}{l}\text { Características de curado, tensión, } \\
\text { abrasión, dureza, resiliencia, } \\
\text { hinchamiento }\end{array}$ & $\begin{array}{l}\text { (Okoh and } \\
\text { Osabohien, 2014) }\end{array}$ \\
\hline $\begin{array}{l}\text { Polvo de } \\
\text { cascarilla de } \\
\text { arroz }\end{array}$ & & $\begin{array}{l}\text { Mezclador de } \\
\text { levas }\end{array}$ & Tensión, impacto, dureza, DMA, SEM & $\begin{array}{l}\text { (Ahmad et al., } \\
\text { 2012) }\end{array}$ \\
\hline
\end{tabular}




\begin{tabular}{|c|c|c|c|c|}
\hline $\begin{array}{l}\text { Silice } \\
\text { derivada de } \\
\text { cascarilla de } \\
\text { arroz }\end{array}$ & XRF, TGA & $\begin{array}{l}\text { Molino de } \\
\text { dos rodillos }\end{array}$ & $\begin{array}{l}\text { Características de curado, tensión, } \\
\text { resistencia al rasgado, dureza, } \\
\text { hinchamiento, densidad de } \\
\text { entrecruzamiento }\end{array}$ & $\begin{array}{l}\text { (Ahmed, Nizami } \\
\text { and Raza, 2013) }\end{array}$ \\
\hline \multirow{2}{*}{$\begin{array}{l}\text { Ceniza de } \\
\text { cascarilla de } \\
\text { arroz }\end{array}$} & $\begin{array}{l}\text { Composición } \\
\text { química, } \\
\text { propiedades físicas }\end{array}$ & $\begin{array}{l}\text { Molino de } \\
\text { dos rodillos }\end{array}$ & Características de curado & $\begin{array}{l}\text { (Da Costa et al., } \\
\text { 2003b) }\end{array}$ \\
\hline & $\begin{array}{l}\text { Composición } \\
\text { química, } \\
\text { propiedades físicas }\end{array}$ & $\begin{array}{l}\text { Molino de } \\
\text { dos rodillos }\end{array}$ & $\begin{array}{l}\text { Características de curado, energía de } \\
\text { activación }\end{array}$ & $\begin{array}{l}\text { (Da Costa et al., } \\
\text { 2003a) }\end{array}$ \\
\hline Fibra de coco & SEM & $\begin{array}{l}\text { Molino de } \\
\text { dos rodillos }\end{array}$ & DMA & $\begin{array}{l}\text { (Geethamma et al., } \\
\text { 2005) }\end{array}$ \\
\hline \multirow{2}{*}{$\begin{array}{l}\text { Fibra de hoja } \\
\text { de piña }\end{array}$} & & $\begin{array}{l}\text { Molino de } \\
\text { dos rodillos }\end{array}$ & $\begin{array}{l}\text { Características de curado, DMTA, tensión, } \\
\text { SEM, }\end{array}$ & $\begin{array}{l}\text { (Hariwongsanupab } \\
\text { et al., 2017) }\end{array}$ \\
\hline & & $\begin{array}{l}\text { Molino de } \\
\text { dos rodillos }\end{array}$ & $\begin{array}{l}\text { Viscosidad mooney, características de } \\
\text { curado, tensión, SEM }\end{array}$ & $\begin{array}{l}\text { (Yantaboot and } \\
\text { Amornsakchai, } \\
\text { 2017) }\end{array}$ \\
\hline \multirow{3}{*}{$\begin{array}{l}\text { Lodo de } \\
\text { mármol }\end{array}$} & XRF, TGA & $\begin{array}{l}\text { Molino de } \\
\text { dos rodillos }\end{array}$ & $\begin{array}{l}\text { Características de curado, tensión, } \\
\text { resistencia al rasgado, dureza, } \\
\text { hinchamiento, densidad de } \\
\text { entrecruzamiento }\end{array}$ & $\begin{array}{l}\text { (Ahmed, Nizami } \\
\text { and Raza, 2013) }\end{array}$ \\
\hline & $\mathrm{BET}, \mathrm{XRF}$ & $\begin{array}{l}\text { Molino de } \\
\text { dos rodillos }\end{array}$ & $\begin{array}{l}\text { Características de curado, tensión, } \\
\text { resistencia al rasgado, dureza, } \\
\text { hinchamiento, densidad de } \\
\text { entrecruzamiento, envejecimiento térmico }\end{array}$ & $\begin{array}{l}\text { (Ahmed et al., } \\
\text { 2013a) }\end{array}$ \\
\hline & XRF & $\begin{array}{l}\text { Molino de } \\
\text { dos rodillos }\end{array}$ & $\begin{array}{l}\text { Características de curado, tensión, } \\
\text { resistencia al rasgado, dureza, compresión } \\
\text { set, resiliencia, abrasión, hinchamiento, } \\
\text { densidad de entrecruzamiento }\end{array}$ & $\begin{array}{l}\text { (Ahmed et al., } \\
\text { 2013b) }\end{array}$ \\
\hline \multirow{4}{*}{$\begin{array}{l}\text { Ceniza de } \\
\text { aceite de } \\
\text { palma }\end{array}$} & SEM, FTIR & $\begin{array}{l}\text { Molino de } \\
\text { dos rodillos }\end{array}$ & $\begin{array}{l}\text { Características de curado, tensión, SEM, } \\
\text { hinchamiento, interacción caucho-fibra, } \\
\text { FTIR }\end{array}$ & $\begin{array}{l}\text { (Ooi, Ismail and } \\
\text { Abu Bakar, 2013) }\end{array}$ \\
\hline & FTIR, SEM & $\begin{array}{l}\text { Molino de } \\
\text { dos rodillos }\end{array}$ & $\begin{array}{l}\text { Características de curado, tensión, } \\
\text { dureza, SEM, hinchamiento y densidad de } \\
\text { entrecruzamiento }\end{array}$ & $\begin{array}{l}\text { (Ooi, Ismail and } \\
\text { Abu Bakar, 2014) }\end{array}$ \\
\hline & $\begin{array}{l}\text { Tamaño de } \\
\text { partícula, SEM, EDX, } \\
\text { XRF, XRD FTIR }\end{array}$ & $\begin{array}{l}\text { Molino de } \\
\text { dos rodillos }\end{array}$ & TGA, tension, SEM & $\begin{array}{l}\text { (Ooi, Ismail and } \\
\text { Bakar, 2013a) }\end{array}$ \\
\hline & & $\begin{array}{l}\text { Molino de } \\
\text { dos rodillos }\end{array}$ & $\begin{array}{l}\text { Características de curado, tensión, dureza, } \\
\text { SEM, hinchamiento, interacciones caucho- } \\
\text { fibra, DMA }\end{array}$ & $\begin{array}{l}\text { (Ooi, Ismail and } \\
\text { Bakar, 2013b) }\end{array}$ \\
\hline
\end{tabular}

Durante el análisis de los diferentes trabajos desarrollados por diferentes autores, se encontró que no todos los autores reportan las condiciones y resultados obtenidos durante la reometría de vulca- nización. La Tabla 6 describe el efecto que tiene la incorporación de algunas cargas posindustriales en caucho natural en los tiempos de vulcanización y en los torques máximo y mínimo. 
TABLA 6. EFECTO DE LA ADICIÓN DE RESIDUOS POSINDUSTRIALES EN LOS PARÁMETROS DE VULCANIZACIÓN DE COMPUESTOS DE CAUCHO NATURAL

\begin{tabular}{|c|c|}
\hline $\begin{array}{l}\text { Residuos } \\
\text { agroindustriales }\end{array}$ & Efecto en los parámetros de vulcanización de los compuestos de caucho natural \\
\hline Bagazo de caña de azúcar & $\begin{array}{l}\text { La adición de estos residuos generó una leve disminución en los tiempos de } \\
\text { vulcanización, dicha disminución estuvo entre } 30 \text { y } 50 \text { segundos. Los torques mínimo y } \\
\text { máximo aumentaron al aumentar la proporción del bagazo, reflejando indirectamente el } \\
\text { aumento en la viscosidad y rendimiento mecánico de los compuestos de caucho natural } \\
\text { (Santos et al., 2014). }\end{array}$ \\
\hline Cáñamo & $\begin{array}{l}\text { Los tiempos de vulcanización y "scorch" disminuyeron como efecto de la adición de } \\
\text { los residuos de cáñamo. En todos los casos, al adicionar los residuos el torque máximo } \\
\text { aumentó (Osabohien and Egboh, 2008). }\end{array}$ \\
\hline Tamarindo & $\begin{array}{l}\text { Al adicionar este residuo, los tiempos de vulcanización y "scorch" disminuyeron } \\
\text { proporcionalmente a la cantidad de residuos adicionados. Los torques máximos } \\
\text { aumentaron a medida que aumentó la proporción de residuos en el caucho natural } \\
\text { (Okoh and Osabohien, 2014). }\end{array}$ \\
\hline Sílice-cascarilla de arroz & $\begin{array}{l}\text { La adición de la ceniza de cascarilla de arroz rica en sílice, genera un aumento general } \\
\text { en la viscosidad y torque máximo de los compuestos de caucho natural, fenómeno que } \\
\text { da indicio de la efecto reforzante de dicha carga, adicionalmente el tiempo "scorch"se } \\
\text { puede ver disminuido mientras el tiempo óptimo de vulcanización de los compuestos } \\
\text { de caucho natural parece no sufrir cambios considerables al adicionar dichas cargas } \\
\text { (Pongdong et al., 2015) o disminuir en pequeña medida en otro estudio (Da Costa } \\
\text { et al., 2003a). En otra investigación realizada, la ceniza de cascarilla de arroz parece } \\
\text { retrasar la reacción de vulcanización en comparación con los compuestos elaborados } \\
\text { con sílice comercial, sin embargo en este trabajo no se comparó directamente el } \\
\text { efecto de la ceniza con el caucho natural sin ningún tipo de carga, con el propósito } \\
\text { de entender el efecto de la ceniza en el caucho natural (Pinpat, Keawwattana and } \\
\text { Tangbunsuk, 2017). }\end{array}$ \\
\hline Fibra de hoja de piña & $\begin{array}{l}\text { Al adicionar los residuos de hoja de piña, los tiempos para comenzar la reacción } \\
\text { de vulcanización disminuyeron levemente, mientras que los tiempos óptimos de } \\
\text { vulcanización disminuyeron casi a la mitad al adicionar los residuos. Las adiciones de los } \\
\text { residuos en el caucho natural generaron un aumento en el torque máximo (Yantaboot } \\
\text { and Amornsakchai, 2017; Hariwongsanupab et al., 2017). }\end{array}$ \\
\hline Lodo de mármol & $\begin{array}{l}\text { Al adicionar este tipo de residuos, el tiempo de inicio de la reacción disminuyó levemente, } \\
\text { mientras que el tiempo de vulcanización no se vio fuertemente influenciado por la } \\
\text { adición de los residuos. Para todos los casos, al adicionar los lodos de mármol los torques } \\
\text { mínimo y máximo aumentaron en comparación al caucho sin ninguna carga (Ahmed, } \\
\text { Nizami and Raza, 2013; Ahmed et al., 2013a). }\end{array}$ \\
\hline Palma de aceite & $\begin{array}{l}\text { Los residuos de palma de aceite no generaron cambios considerables en los tiempos } \\
\text { "scorch" de los compuestos de caucho natural, y disminuyeron levemente el tiempo } \\
\text { de vulcanización de los mismos. El torque mínimo no sufrió cambios al adicionar los } \\
\text { residuos, mientras que el torque máximo presentó un leve aumento (Ooi, Ismail and Abu } \\
\text { Bakar, 2013). }\end{array}$ \\
\hline
\end{tabular}


Figura 3. Micrografías SEM de algunas cargas agroindustriales mezcladas con caucho natural

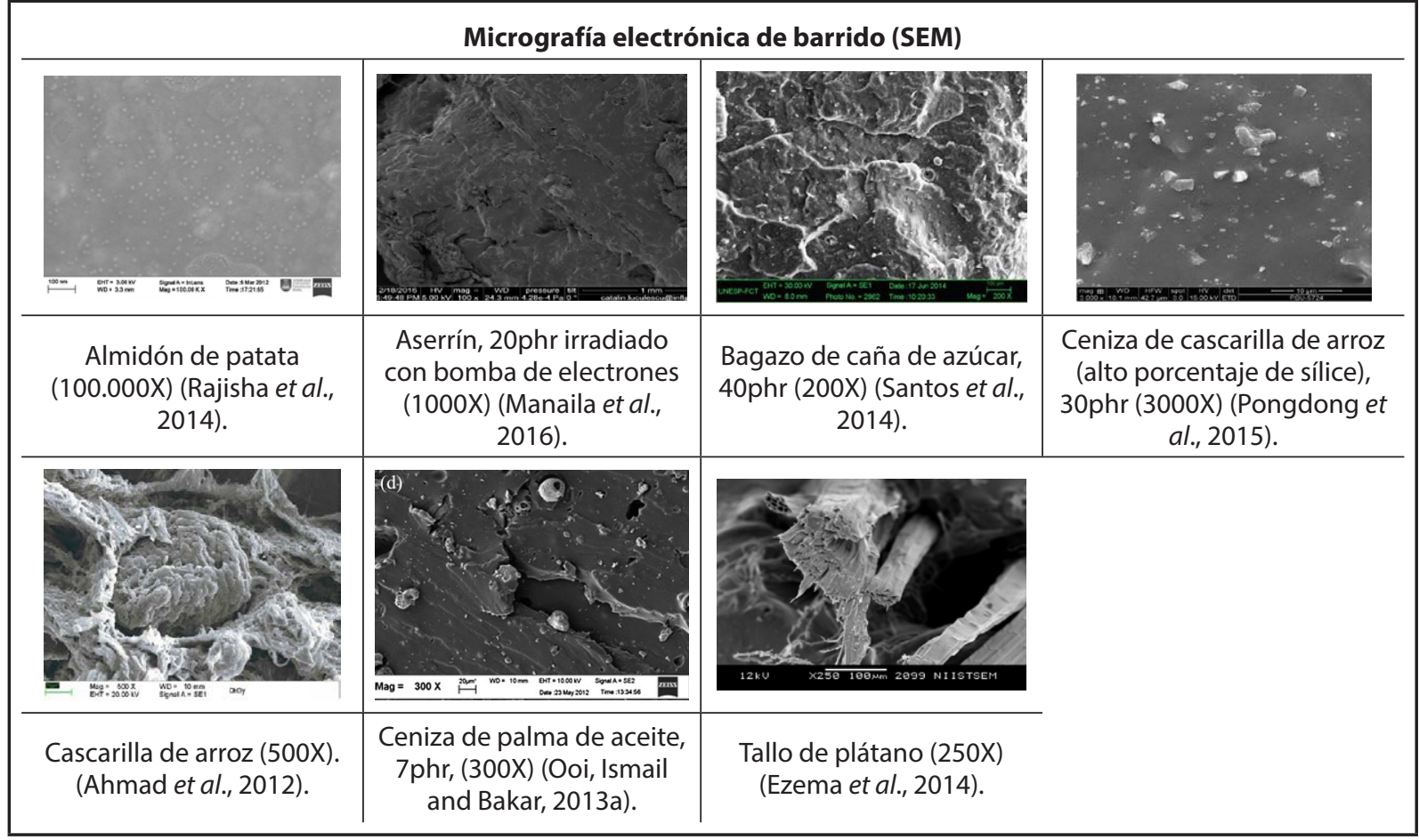

Figura 4. Módulo al 100\% de deformación en tensión de algunas cargas agroindustriales y comerciales mezcladas con caucho natural

(Vargas et al., 2016; Kaewasakul, 2013)

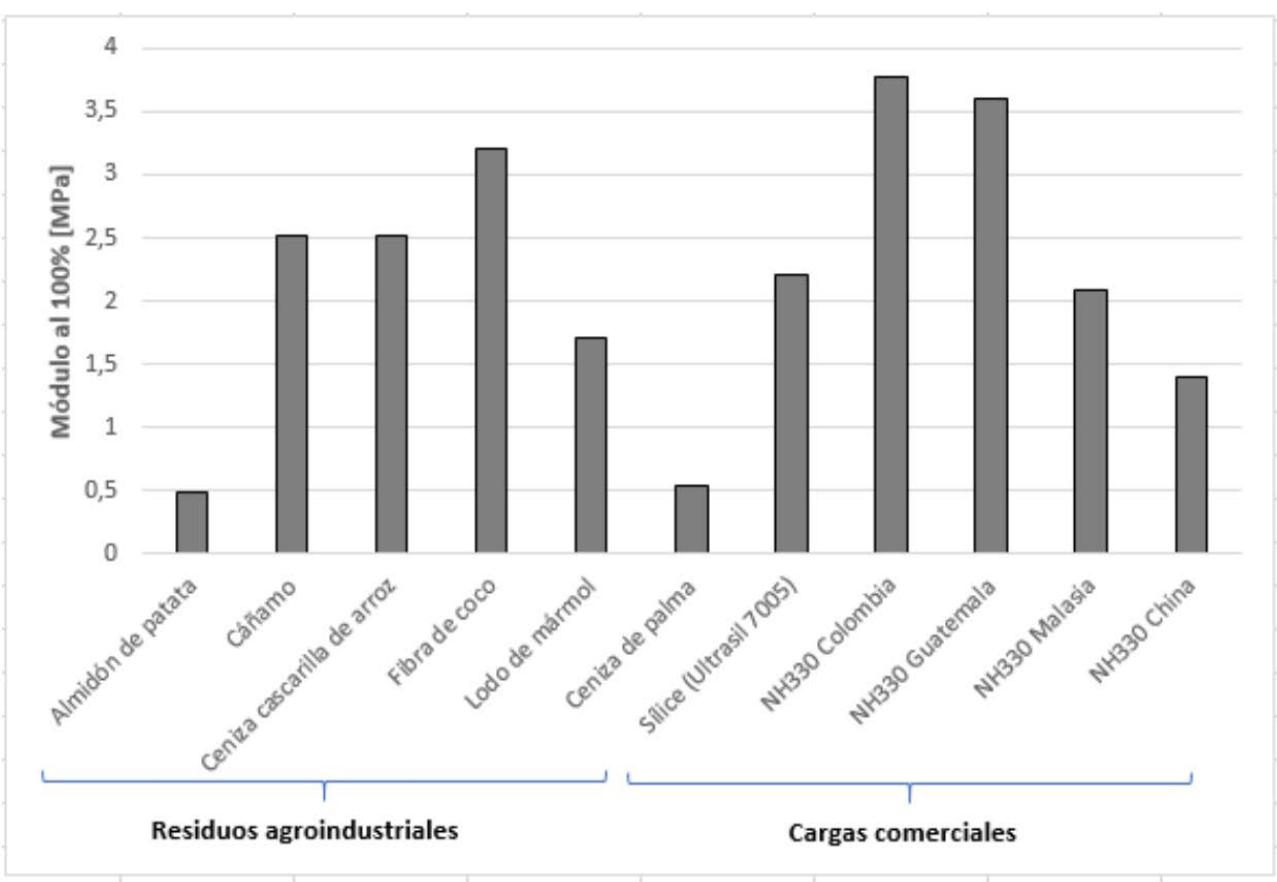


Los tiempos de vulcanización son un parámetro que está directamente relacionado con los tiempos de proceso para la producción de cualquier producto de caucho vulcanizado. Si los tiempos de vulcanización disminuyen como efecto de la adición de los residuos agroindustriales, puede entonces influir positivamente en el proceso productivo, ya que los tiempos necesarios para la producción de un producto de caucho vulcanizado puede ser menor. El efecto de los residuos en los tiempos de vulcanización puede deberse al $\mathrm{pH}$ o naturaleza química, en algunos casos el pH puede ser ácido, por lo que puede generar un efecto activador de la reacción de vulcanización, acelerando tanto el comienzo de la reacción como los tiempos para lograr el 100\% de la vulcanización $\mathrm{t}_{100}$ (Urrego Yepes et al., 2018; Ravichandran and Natchimuthu, 2005a; b).

$\mathrm{Al}$ aumentar los torques máximos de los compuestos de caucho natural mezclado con los residuos posindustriales, también se espera que aumente el rendimiento mecánico de estos compuestos (Urrego Yepes et al., 2018).

Como fue discutido anteriormente, la morfología de las cargas, la incorporación y la interacción de los diferentes residuos agroindustriales con el caucho natural puede ser evaluado mediante técnicas microscópicas como por ejemplo la microscopía electrónica de barrido (SEM). En la Figura 3 se observan diferentes cargas mezcladas con caucho natural, las imágenes escogidas tienen un rango aproximado de aumentos, con el propósito de generar una comparación cualitativa de la interacción de las diferentes cargas con el caucho natural, a excepción de los nano cristales de almidón de patata que debido a su tamaño nanoscópico, los aumentos fueron de 100.000X.

La adición de los diferentes residuos agroindustriales en el caucho natural genera cambios en el rendimiento mecánico de los compuestos. El comportamiento en tensión de los compuestos permite evaluar propiedades como la resistencia máxima, la rigidez y capacidad de elongación de los materiales. En los cauchos se evalúa la rigidez como el esfuerzo a una deformación establecida, generalmente en porcentaje de deformación (100 y 300), de esta manera se puede establecer que material reforzante genera una mayor rigidez en los compuestos de caucho natural. En la Figura 4 se presenta un comparativo del comportamiento del módulo al 100\% de deformación (M100), donde se comparan compuestos de caucho natural obtenidos con cargas de residuos agroindustriales y comerciales de negro de humo 330 y sílice Ultrasil 7005, donde se observa que algunos compuestos de caucho natural reforzados con residuos agroindustriales obtienen niveles de M100 similares a los de los compuestos reforzados con cargas comerciales. Esto permite la posibilidad de desarrollar compuestos de caucho natural con estos residuos agroindustriales, en aplicaciones similares a las establecidas en cauchos naturales reforzados con cargas comerciales.

\section{Conclusiones}

Con el fin de evaluar posibles usos de residuos agroindustriales, se revisó la alternativa de su incorporación en compuestos de caucho natural. Previo a la caracterización físico química de cada residuo, se encuentra que existen diversos tipos de refuerzos que pueden obtenerse para incorporar en la matriz de caucho natural; en algunos casos se requieren algunos tratamientos previos para asegurar un adecuado acople con la matriz del compuesto. Como se encuentra detallado en el presente trabajo, los métodos de incorporación de los refuerzos obtenidos a partir de residuos agroindustriales se pueden realizar con los procedimientos y equipos estándar empleados en el desarrollo de compuestos de caucho natural típicos, empleados para la fabricación con refuerzos comerciales como el negro de humo y sílice.

En cada caso de refuerzo empleado, se expone el efecto en el proceso de vulcanización, detallando en qué condiciones se varían parámetros tales como tiempos de vulcanización y scorch, torques máximos y mínimos. Finalmente, se recopilaron las diferentes caracterizaciones fisicomecánicas de los compuestos de caucho natural obtenidos con refuerzos de residuos agroindustriales, realizando 
comparaciones morfológicas de los compuestos y una evaluación comparativa numérica de una propiedad mecánica típica en compuestos de caucho para determinar su rigidez, como lo es el módulo al $100 \%$ de deformación. Esta evaluación, permitió establecer que refuerzos como el cáñamo, cascarilla de arroz y fibra de coco tienen niveles similares a los registrados con refuerzos comerciales típicos como el negro de humo y sílice.

\section{Agradecimientos}

Los autores agradecen al Instituto Tecnológico Metropolitano (ITM) por sus aportes institucionales.

\section{Referencias}

Ahmad, I., Lane, C.E., Mohd, D.H. and Abdullah, I., 2012. Electron-beam-irradiated rice husk powder as reinforcing filler in natural rubber/high-density polyethylene (NR/HDPE) composites. Composites Part B: Engineering, [online] 43(8), pp.3069-3075. Available at: <http://dx.doi.org/10.1016/j.compositesb.2012.04.071>.

Ahmed, K., Nizami, S.S. and Raza, N.Z., 2013. Characteristics of natural rubber hybrid composites based on marble sludge/carbon black and marble sludge/ rice husk derived silica. Journal of Industrial and Engineering Chemistry, [online] 19(4), pp.1169-1176. Available at: <http://www.sciencedirect.com/ science/article/pii/S1226086X12004340> [Accessed 5 Mar. 2015].

Ahmed, K., Nizami, S.S., Raza, N.Z. and Habib, F., 2013a. The effect of silica on the properties of marble sludge filled hybrid natural rubber composites. Journal of King Saud University - Science, [online] 25(4), pp.331-339. Available at: <http://dx.doi. org/10.1016/j.jksus.2013.02.004>.

Ahmed, K., Nizami, S.S., Raza, N.Z. and Mahmood, K., 2013b. Effect of micro sized marble sludge on physical properties of natural rubber composites. Chemical Industry and Chemical Engineering Quarterly, [online] 19(2), pp.281-293. Available at: <http:// www.doiserbia.nb.rs / Article.aspx?ID =1451 93721200062A>.

Ajila, C.M., Brar, S.K., Verma, M. and Prasada Rao, U.J.S., 2012. Sustainable Solutions for Agro Processing
Waste Management: An Overview. In: Environmental Protection Strategies for Sustainable Development. [online] Dordrecht: Springer Netherlands, pp.65-109. Available at: <http://link.springer. com/10.1007/978-94-007-1591-2_3> [Accessed 23 Jan. 2019].

Akinlabi, A.K., Okieimen, F.E., Egharevba, F. and Malomo, D., 2006. Investigation of the effect of mixing schemes on rheological and physico-mechanical properties of modified natural rubber blends. Materials and Design, 27(9), pp.783-788.

AL-nesrawy, S.H., Al-maamori, M., A.S.Hassani and Harith.I.Jaafar, 2014. Effect of mixture of Reclaimed tire and Carbon Black Percent on the Mechanical properties of SBR/NR blends. International Journal of Advanced Research, 2(3), pp.234-243.

ASTM International, 2013. ASTM D3182 - 07. Standard Practice for Rubber-Materials, Equipment, and Procedures for Mixing Standard Compounds and Preparing Standard Vulcanized Sheets.

Cardona, N., Velásquez, S. and Giraldo, D., 2017. Characterization of Leather Wastes from Chrome Tanning and its Effect as Filler on the Rheometric Properties of Natural Rubber Compounds. Journal of Polymers and the Environment, 25(4), pp.1190-1197.

Da Costa, H.M., Visconte, L.L.Y., Nunes, R.C.R. and Furtado, C.R.G., 2003a. Rice-husk-ash-filled natural rubber. II. Partial replacement of commercial fillers and the effect on the vulcanization process. Journal of Applied Polymer Science, 87(9), pp.1405-1413.

Da Costa, H.M., Visconte, L.L.Y., Nunes, R.C.R. and Furtado, C.R.G., 2003b. Rice husk ash filled natural rubber. III. Role of metal oxides in kinetics of sulfur vulcanization. Journal of Applied Polymer Science, 90(6), pp.1519-1531.

Dimier, F., Vergnes, B. and Vincent, M., 2004. Relationships between mastication conditions and rheological behavior of a natural rubber. Rheologica Acta, 43(2), pp.196-202.

Domínguez-Bocanegra, A.R., Torres-Muñoz, J.A. and López, R.A., 2015. Production of Bioethanol from agro-industrial wastes. Fuel, [online] 149, pp.85-89. Available at: <http://www.sciencedirect.com.itm.elogim. com/science/article/pii/S0016236114009314> [Accessed 24 Oct. 2017].

Donnet, J.-B., 1993. Carbon Black: Science and Technology, Second Edition - CRC Press Book. Second Edi 
ed. [online] CRC Press. Available at: <https://www. crcpress.com/Carbon-Black-Science-and-Technology-Second-Edition/Donnet/9780824789756> [Accessed 27 Jul. 2015].

Eastern Research Group, I., TetraTech Consulting Group and Federation of Indian Chambers of Commerce and Industry, 2011. Resource assessment for livestock and agro-industrial wastes- India.

Ezema, I.C., Menon, A.R.R., Obayi, C.S. and Omah, A.D., 2014. Effect of Surface Treatment and Fiber Orientation on the Tensile and Morphological Properties of Banana Stem Fiber Reinforced Natural Rubber Composite. Journal of Mineral and Material Characterization and Engineering, 2(May), pp.216-222.

Fernandez, A.,Saffe, A., Pereyra, R., Mazza, G. and Rodriguez, R., 2016. Kinetic study of regional agro-industrial wastes pyrolysis using non-isothermal TGA analysis. [online] Available at: <https://ac-els-cdn-com.itm. elogim.com:2443/S135943111630998X/1-s2.0S135943111630998X-main.pdf?_tid=da95367eb8d9-11e7-bff0-00000aacb35e\&acdnat $=1508863$ 327_22487b4f04bdac73512d1d9a718d6914> [Accessed 24 Oct. 2017].

Ferreira-Leitão, V., Gottschalk, L.M.F., Ferrara, M.A., Nepomuceno, A.L., Molinari, H.B.C. and Bon, E.P.S., 2010. Biomass Residues in Brazil: Availability and Potential Uses. Waste and Biomass Valorization, [online] 1(1), pp.65-76. Available at: <http://link.springer. com/10.1007/s12649-010-9008-8> [Accessed 23 Jan. 2019].

Fu, J.F., Yu, W.Q., Dong, X., Chen, L.Y., Jia, H. Sen, Shi, L.Y., Zhong, Q.D. and Deng, W., 2013. Mechanical and tribological properties of natural rubber reinforced with carbon blacks and Al203 nanoparticles. Materials and Design, [online] 49, pp.336-346. Available at: <http://dx.doi.org/10.1016/j.matdes.2013.01.033>.

Geethamma, V.G., Kalaprasad, G., Groeninckx, G. and Thomas, S., 2005. Dynamic mechanical behavior of short coir fiber reinforced natural rubber composites. Composites Part A: Applied Science and Manufacturing, [online] 36(11), pp.1499-1506. Available at: <http://www.sciencedirect.com/science/article/pii/S1359835X05001004> [Accessed 13 Jul. 2015].

Geethamma, V.G., Thomas Mathew, K., Lakshminarayanan, R. and Thomas, S., 1998. Composite of short coir fibres and natural rubber: effect of chemical modification, loading and orientation of fibre. Polymer, [online] 39(6-7), pp.1483-1491. Available at: <http://www.sciencedirect.com/science/article/ pii/S0032386197004229> [Accessed 13 Jul. 2015].

Goldberg, E.D., 1985. Black carbon in the environment: properties and distribution. [online] Available at: <https://books.google.com.co/books/ about/Black_Carbon_in_the_Environment. $\mathrm{html}$ ?id $=4 \mathrm{nMYAQAAIAA}$ ]\&redir_esc $=\mathrm{y}>$ [Accessed 31 Jan. 2019].

González-Velandia, K.-D., Daza-Rey, D., Caballero-Amado, P.-A. and Martínez-González, C., 2016. Evaluación de las propiedades físicas y químicas de residuos sólidos orgánicos a emplearse en la elaboración de papel. Luna Azul, [online] 43(43), pp.499-517. Available at: <http://200.21.104.25/lunazul/index. php?option=com_content\&view $=$ article\&id=210>.

Gonzalez, L.V.P.S.P.M.G.P.A.G.A., 2018. Aprovechamiento de residuos agroindustriales en Colombia.

Guzmán, M.F.S. and ruiz, D.D.P., 2011. Concreto preparado con residuos industriales: resultado de alianza empresa universidad. Revista Educación en Ingeniería, [online] 6(11), pp.1-11. Available at: <https:// www.educacioneningenieria.org/index.php/edi/ article/view/116> [Accessed 23 Jan. 2019].

Hariwongsanupab, N., Thanawan, S., Amornsakchai, T., Vallat, M.F. and Mougin, K., 2017. Improving the mechanical properties of short pineapple leaf fiber reinforced natural rubber by blending with acrylonitrile butadiene rubber. Polymer Testing, [online] 57, pp.94-100. Available at: <http://dx.doi. org/10.1016/j.polymertesting.2016.11.019>.

Hashim, F., Ismail, H. and Rusli, A., 2017. Effect of fibre treatments on tensile properties of ethylene vinyl acetate/natural rubber/mengkuang leaf fibre (EVA/NR/MLF) thermoplastic elastomer composites. In: Proceeding of the 3rd International Conference of Global Network for Innovative Technology 2016. [online] p.040013. Available at: <http://aip. scitation.org/doi/abs/10.1063/1.4993355> [Accessed 29 Oct. 2017].

Imanah, J.E. and Okieimen, F.E., 2003. Rheological and Mechanical Properties of Natural Rubber Reinforced with Agricultural Byproduct. Journal of Applied Polymer Science, 90(13), pp.3718-3722. 
Iqbal, M.Z., Abdala, A.A., Mittal, V., Seifert, S., Herring, A.M. and Liberatore, M.W., 2016. Processable conductive graphene/polyethylene nanocomposites: Effects of graphene dispersion and polyethylene blending with oxidized polyethylene on rheology and microstructure. Polymer, 98, pp.143-155.

Jaramillo Pineda, O.J., Gómez García, M.Á. and Alzate, J.F., 2012. Removal of ethanolic fermentation inhibitors using polydimethylsiloxane (PDMS) membranes by pervaporation. Revista ION, 25(1), pp.51-59.

Kaewasakul, W., 2013. Silica-Reinforced Natural Rubber for low rolling resistance, energy-saving tires. University of Twente.

Kanking, S., Niltui, P., Wimolmala, E. and Sombatsompop, N., 2012. Use of bagasse fiber ash as secondary filler in silica or carbon black filled natural rubber compound. Materials \& Design, [online] 41, pp.74-82. Available at: <http://www.sciencedirect.com/science/article/pii/S0261306912002853> [Accessed 13 Jul. 2015].

Leblanc, J.L., 2002. Rubber-filler interactions and rheological properties in filled compounds. Progress in Polymer Science (Oxford), 27, pp.627-687.

Lecorre, D.S., Bras, J. and Dufresne, A., 2012. Influence of the botanic origin of starch nanocrystals on the morphological and mechanical properties of natural rubber nanocomposites. Macromolecular Materials and Engineering, 297(10), pp.969-978.

López-Miranda, J., Soto-Cruz, N.O., Rutiaga-Quiñones, O.M., Medrano-Roldán, H. and Arévalo-Niño, K., 2009. Optimización del proceso de obtención enzimática de azúcares fermentables a partir de aserrín de pino. Rev. Int. Contam. Ambient, 25(2), pp.95-102.

Maiti, S., Sarma, S.J., Brar, S.K., Le Bihan, Y., Drogui, P., Buelna, G., Verma, M., Jyoti Sarma, S., Kaur Brar, S., Le Bihan, Y., Drogui, P., Buelna, G. and Verma, M., 2016. Agro-industrial wastes as feedstock for sustainable bio-production of butanol by Clostridium beijerinckii. Food and Bioproducts Processing, [online] 98, pp.217-226. Available at: <http://dx.doi. org/10.1016/j.fbp.2016.01.002> [Accessed 24 Oct. 2017].

Manaila, E., Stelescu, M.D., Craciun, G. and Ighigeanu, D., 2016. Wood sawdust/natural rubber ecocomposites cross-linked by electron beam irradiation. $\mathrm{Ma}$ terials, 9(7), pp.1-23.
Martínez, J.D., Murillo, R. and García, T., 2013. Production of carbon black from the waste tires pyrolysis. Bol. Grupo Español Carbón, (i), pp.10-14.

McPhail, S.J., Cigolotti, V. and Moreno, A., 2012. Fuel Cells in the Waste-to-Energy Chain. Green Energy and Technology. [online] London: Springer London. Available at: <http://link.springer.com/10.1007/978-14471-2369-9> [Accessed 23 Jan. 2019].

Mohammed, L., Ansari, M.N.M., Pua, G., Jawaid, M. and Islam, M.S., 2015. A Review on Natural Fiber Reinforced Polymer Composite and Its Applications. International Journal of Polymer Science, [online] 2015, pp.1-15. Available at: <http://www.hindawi.com/ journals/ijps/2015/243947/>.

Nigam, P.S. and Pandey, A., 2009. Biotechnology for agroindustrial residues utilisation: utilisation of agroresidues. Springer.

Obasi, N.E., Okorocha, C. and Orisakwe, O.F., 2013. Production and evaluation of Velvet tamarind (Dialium guineese wild) candy. European Journal of Food Science and Technology, 1(1), pp.1-8.

Okoh, B.E. and Osabohien, E., 2014. The reinforcing potentials of Velvet tamarind seed shell as filler in natural rubber compounds. 8(October), pp.2367-2376.

Ooi, Z.X., Ismail, H. and Abu Bakar, A., 2013. Synergistic effect of oil palm ash filled natural rubber compound at low filler loading. Polymer Testing, 32(1), pp.38-44.

Ooi, Z.X., Ismail, H. and Abu Bakar, A., 2014. Curing characteristics, mechanical, morphological, and swelling assessment of liquid epoxidized natural rubber coated oil palm ash reinforced natural rubber composites. Polymer Testing, [online] 33(October 2016), pp.145-151. Available at: <http://dx.doi. org/10.1016/j.polymertesting.2013.11.007>.

Ooi, Z.X., Ismail, H. and Bakar, A.A., 2013a. Characterization of oil palm ash (OPA) and thermal properties of OPA-filled natural rubber compounds. Journal of Elastomers and Plastics, 47(1), pp.1-15.

Ooi, Z.X., Ismail, H. and Bakar, A.A., 2013b. Optimisation of oil palm ash as reinforcement in natural rubber vulcanisation: A comparison between silica and carbon black fillers. Polymer Testing, 32, pp.625-630.

Osabohien, E. and Egboh, S.H.O., 2008. Utilization of bowstring hemp fiber as a filler in natural rubber compounds. Journal of Applied Polymer Science, [online] 
107(1), pp.210-214. Available at: <http://doi.wiley. com/10.1002/app.27012> [Accessed 13 Jul. 2015].

P, M., TE, M. and SP, H., 2016. Natural Rubber and Reclaimed Rubber Composites-A Systematic Review. Polymer science, [online] 2(1), pp.1-19. Available at: <http://polymerscience.imedpub.com/naturalrubber-and-reclaimed-rubber-compositesa-systematic-review.php?aid=11066>.

Panyasart, K., Chaiyut, N., Amornsakchai, T. and Santawitee, 0., 2014. Effect of surface treatment on the properties of pineapple leaf fibers reinforced polyamide 6 composites. Energy Procedia, [online] 56(56), pp.406-413. Available at: <http://creativecommons.org/licenses/by-nc-nd/3.0/> [Accessed 1 Nov. 2017].

Patnaik, B.T. and Brown, B., 2010. Carbon black : why quality matters. Rubber \& Plastics News, [online] pp.1618. Available at: <www.rubbernews.com>.

Pinchuk, L., Jurkowski, B., Jurkowska, B., Kravtsov, A. and Goldade, V., 2001. On some variations in rubber charge state during processing. European Polymer Journal, [online] 37(11), pp.2239-2243. Available at: <https://www.sciencedirect.com/science/article/pii/S0014305701001173> [Accessed 31 Jan. 2019].

Pinpat, W., Keawwattana, W. and Tangbunsuk, S., 2017. Effect of Ashes as Biomass in Silica Filled Natural Rubber. Key Engineering Materials, [online] 735, pp.153-157. Available at: <http://www.scientific. net/KEM.735.153> [Accessed 2 Nov. 2017].

Pongdong, W., Nakason, C., Kummerlöwe, C. and Vennemann, N., 2015. Influence of Filler from a Renewable Resource and Silane Coupling Agent on the Properties of Epoxidized Natural Rubber Vulcanizates. 2015.

Posada-Correa, J.C., Jaramillo-Zapata, L.Y., Villegas-Bolaños, P.A., García, L.A. and Vargas-Isaza, C.A., 2014. Estudio comparativo de negro de humo y alúmina como cargas reforzantes en mezclas de caucho natural. Revista de la facultad de ingenierías fisicomecánicas, [online] 13(2), pp.59-67. Available at: $<$ http://revistas.uis.edu.co/index.php/revistauisingenierias/article/view/4464>.

Rajisha, K.R., Maria, H.J., Pothan, L.A., Ahmad, Z. and Thomas, S., 2014. Preparation and characterization of potato starch nanocrystal reinforced natural rubber nanocomposites. International Journal of Biological Macromolecules, [online] 67, pp.147153. Available at: <http://dx.doi.org/10.1016/j. ijbiomac.2014.03.013>.

Rattanasom, N. and Prasertsri, S., 2012. Mechanical properties, gas permeability and cut growth behaviour of natural rubber vulcanizates: Influence of clay types and clay/carbon black ratios. Polymer Testing, [online] 31(5), pp.645-653. Available at: <http:// dx.doi.org/10.1016/j.polymertesting.2012.04.001> [Accessed 29 May 2015].

Ravichandran, K. and Natchimuthu, N., 2005a. Natural rubber: leather composites. Polímeros, [online] 15(2), pp.102-108. Available at: <http://www.scielo.br/scielo.php?script=sci_arttext\&pid=S0104$14282005000200008 \& \operatorname{lng}=$ en $\& \mathrm{nrm}=\mathrm{i}$ so \& $\operatorname{lng}=$ en>.

Ravichandran, K. and Natchimuthu, N., 2005b. Vulcanization characteristics and mechanical properties of natural rubber-scrap rubber compositions filled with leather particles. Polymer International, 54(3), pp.553-559.

Rodolfo Ruiz Posada, Julio César Rodríguez Galvis and Luis 0. Hernández, 2014. Utilización del fruto de palma de aceite en la alimentacion de pollos de engorde en fase de finalizacion - Engormix. [online] Available at: <https://www.engormix.com/avicultura/articulos/utilizacion-fruto-palma-aceite-t30968.htm> [Accessed 23 Jan. 2019].

Santos, A., Villegas, N. and Betancourt, J., 2012. Residuo de mármol como insumo en la construcción civil: diagnóstico de la Comarca Lagunera. Revista de la construcción, [online] 11(2), pp.17-26. Available at: $\quad$ http://www.scielo.cl/scielo.php?script=sci_ arttext\&pid=S0718-915X2012000200003\&lng=en \&nrm=iso\&tlng=en> [Accessed 1 Nov. 2017].

Santos, N.S., Silva, M.R. and Alves, J.L., 2017. Reinforcement of a biopolymer matrix by lignocellulosic agro-waste. Procedia Engineering, [online] 200, pp.422-427. Available at: <www.elsevier.com/locate/procedia> [Accessed 24 Oct. 2017].

Santos, R.J. dos, Agostini, D.L. da S., Cabrera, F.C., Reis, E.A.P. dos, Ruiz, M.R., Budemberg, E.R., Teixeira, S.R. and Job, A.E., 2014. Sugarcane bagasse ash: new filler to natural rubber composite. Polímeros, [online] 24(6), pp.646-653. Available at: <http://www.scielo.br/scielo.php?script=sci_arttext\&pid=S0104$14282014000600004 \& \operatorname{lng}=$ en\&tlng=en $>$. 
Sorahan, T. and Harrington, J.M., 2007. A "lugged" analysis of lung cancer risks in UK carbon black production workers, 1951-2004. American Journal of Industrial Medicine, [online] 50(8), pp.555-564. Available at: <http://www.ncbi.nlm.nih.gov/ pubmed/17516558> [Accessed 31 Jan. 2019].

Stelescu, M.-D., Manaila, E., Craciun, G. and Dumitrascu, M., 2014. New green polymeric composites based on hemp and natural rubber processed by electron beam irradiation. The Scientific World Journal, 2014.

Urrego Yepes, W., Cardona, N., Velasquez, S.M., Giraldo Vásquez, D.H. and Posada, J.C., 2018. Mechanical and rheometric properties of natural rubber composites filled with untreated and chemically treated leather wastes. Journal of Composite Materials, [online] p.002199831880519. Available at: <http://journals. sagepub.com/doi/10.1177/0021998318805195>.

Urrego Yepes, W., Cardona Vásquez, N., Velásquez Restrepo, S.M. and Abril Carrascal, C., 2017. Revisión - Caracterización de compuestos de caucho con residuos de cuero posindustrial/Review - Characterization of rubber compounds with post-industrial leather waste. Prospectiva, [online] 15(2), p.13. Available at: <http://ojs.uac.edu.co/index.php/prospectiva/article/view/776>.

Vargas, C.A., Sierra, J.D., Posada, J.C., Garcia, L.A. and Zapata, L.J., 2016. Reinforcement effect of carbon black in Colombian natural rubber: Benchmarking with Guatemala rubber. Journal of Elastomers and Plastics, [online] pp.1-14. Available at: <http://jep.sagepub.com/cgi/doi/10.1177/0095244316645953>.

Verónica Benavente, Calabuig, E. and Fullana, A., 2015. Upgrading of moist agro-industrial wastes by hydrothermal carbonization. Journal of Analytical and Applied Pyrolysis, [online] 113, pp.8998. Available at: <https://ac-els-cdn-com.itm. elogim.com:2443/S0165237014002770/1-s2.0S0165237014002770-main.pdf?_tid=3aed8cd4b8d9-11e7-8b3b-00000aab0f27\&acdnat $=1508863$ 059_2a64eb6b173af7a739da8fd77975df21> [Accessed 24 Oct. 2017].

Virmond, E., Rocha, J.D., Moreira, R.F.P.M. and José, H.J., 2013. Valorization of agroindustrial solid residues and residues from biofuel production chains by thermochemical conversion: a review, citing Brazil as a case study. Brazilian Journal of Chemical Engineering, [online] 30(2), pp.197-230. Available at: <http://www.scielo.br/scielo.php?script=sci arttext\&pid=S0104-66322013000200001\&lng=en \&tlng=en $>$ [Accessed 23 Jan. 2019].

WANG, M.-J., GRAY, C.A., REZNEK, S.R., MAHMUD, K., KUTSOVSKY, Y. and Cabot Corporation, 2002. Carbon black. In: Encyclopedia of Polymer Science and Technology. John Wiley \& Sons, Inc., pp.52-91.

WHITE, J.L., 1994. Rheological Behavior and Processing of Unvulcanized Rubber. Science and Technology of Rubber, [online] pp.257-338. Available at: <https://www.sciencedirect.com/science/article/ pii/B9780080516677500111> [Accessed 31 Jan. 2019].

Yantaboot, K. and Amornsakchai, T., 2017. Effect of mastication time on the low strain properties of short pineapple leaf fiber reinforced natural rubber composites. Polymer Testing, [online] 57, pp.31-37. Available at: <http://dx.doi.org/10.1016/j.polymertesting.2016.11.006>.

Yeşilay, S., Çakı, M. and Ergun, H., 2017. Usage of marble wastes in traditional artistic stoneware clay body. Ceramics International, 43(12), pp.8912-8921.

Zahan, Z., Othman, M.Z. and Muster, T.H., 2017. Anaerobic digestion/co-digestion kinetic potentials of different agro- industrial wastes: A comparative batch study for $\mathrm{C} / \mathrm{N}$ optimisation. Waste Management. [online] Available at: <https://ac-els-cdn-com.itm. elogim.com:2443/S0956053X17305871/1-s2.0S0956053X17305871-main.pdf?_tid=578ffb22b8d6-11e7-976b-00000aab0f26\&acdnat=150886 1819_2d03ce8af6452c7e632eb6d73f5d4d9e> [Accessed 24 Oct. 2017].

\section{PARA CITAR ESTE ARTÍCULO / TO REFERENCE THIS ARTICLE / PARA CITAR ESTE ARTIGO /}

Vargas Isaza, C.A.; Urrego Yepes, W.; Arbeláez Vergara, M.Y.; Sánchez Manosalba. C.J. (2019). Revisión- Comportamiento fisicoquímico de compuestos de caucho natural al adicionar residuos agroindustriales como cargas reforzantes. Revista EIA, 16(32), Julio-Diciembre, pp. 129-149. [Online]. Disponible en: https://doi.org/10.24050/reia.v16i32.1214 